\title{
Non-invasive prenatal testing for detection of trisomy 13, 18, 21 and sex chromosome aneuploidies in 8594 cases
}

\author{
Yunyun Zheng, Shanning Wan, Yinghui Dang, Tingting Song, Biliang Chen, Jianfang Zhang \\ Department of Obstetrics and Gynecology, The First Affiliated Hospital Of AFMU (Air Force Medical University), Xi'an, Shaanxi, China
}

\begin{abstract}
Objectives: Cell-free fetal DNA has been widely used in prenatal genetic testing during recent years. We explored the feasibility of non-invasive prenatal testing (NIPT) for analysis of common fetal aneuploidies among pregnancies in northwest China.

Material and methods: A total of 8594 maternal blood samples were collected from October 2014 to December 2017 in the Department of Obstetrics and Gynecology at the First Affiliated Hospital of the Air Force Medical University. Cases with positive screening results by NIPT detection were validated using karyotype analysis.

Results: Of 8594 clinical pregnancies, 88 had positive NIPT results and 78 of 88 (88.6\%) positive NIPT results were shown to be false-positive by amniotic fluid puncture and chromosome karyotyping analysis. There were 44 cases (49.44\%) with trisomy 21,18 , and 13 syndromes (30 cases of trisomy 21,9 cases of trisomy 18 , and 5 cases of trisomy 13 ). There were 44 cases $(50.56 \%)$ with sex chromosome abnormalities, including 11 cases with Turner syndrome $(45, X), 17$ cases with Triple X syndrome (47, XXX), 2 cases with Klinefelter syndrome (47, XXY), and 14 cases with 47, XYY syndrome (47, XYY).

Conclusions: The accuracy, specificity, high efficiency, and acceptance of NIPT can effectively avoid birth defects and improve the quality of the birth population. We should deepen mining and analysis of the clinical data and explore ways to use NIPT. It is recommended that the NIPT guidelines be extended to low-risk patients to further explore the impact of a significant increase in screening.

Key words: non-invasive prenatal testing; fetal aneuploidy; karyotype analysis
\end{abstract}

Ginekologia Polska 2019; 90, 5: 270-273

\section{INTRODUCTION}

In 1997, cell-free fetal DNA fragments were discovered in maternal blood, and in 2011 non-invasive prenatal testing (NIPT) analyzed cell-free fetal DNA via massive parallel sequencing. The testing was introduced into clinical practice and became more widely available [1], Clinical trial data and reports based on actual clinical experience have demonstrated efficacy in screening for the most common autosomies that occur at birth (trisomies 21, 18, and 13), and sex chromosome aneuploidies [2-5]. Some studies have reported a detection and false-positive rates of $99.2 \%$ and $0.09 \%$ for trisomy $21,96.3 \%$ and $0.13 \%$ for trisomy 18 , and $91.0 \%$ and $0.13 \%$ for trisomy 13 [6]. Other studies have reported trisomy 21 detection rates of $98.6 \%$ to > 99\% [7-9], and the trisomy 18 detection rate is $>97.2 \%$ [8]. According to a meta-analysis conducted by Taylor-Phillip et al. [10], the pooled sensitivity was $99.3 \%$ for trisomy $21,97.4 \%$ for tri- somy 18 , and $97.4 \%$ for trisomy 13 . Positive predictive values are significantly lower, particularly in low-risk populations [11]. Therefore, NIPT is an accurate screening test that offers the opportunity to improve the detection of aneuploidies, while reducing the use of invasive diagnostic procedures.

In our hospital we have used NIPT since 2014 and $>8594$ pregnant women have undergone NIPT. We mined and analyzed the clinical data and showed that NIPT is feasible for prenatal screening of common chromosomal abnormalities. Herein we explored the use of NIPT from the perspective of evidence-based medicine.

\section{MATERIAL AND METHODS}

Non-invasive prenatal testing

A total of 8594 pregnant women who underwent NIPT and prenatal diagnosis at the First Affiliated Hospital of the Air Force Medical University from October 2014 to Decem- 
ber 2017 were enrolled in this study. The inclusion criteria were as follows: (i) singleton pregnancy; (ii) 18-50 years of age; and (iii) gestational age 13-27 weeks. All patients had a risk indication, which included advanced maternal age ( $\geq 35$ years), a sonographic abnormality, a history of a prior aneuploidy, and abnormal traditional aneuploidy screening. Informed consent was obtained from the patients prior to enrollment in the study. Standard procedures were followed, including plasma separation, isolation of cell-free DNA, library construction (end repair, joint connection, and gap repair), an accurate quantitative library, sequencing detection, and bioinformatics analysis. An IIlumina NextSeq CN500 or lon Torrent Sequencing System (BioelectronSeq 4000) was used for sequencing detection. Sequencing data were analyzed using a proprietary algorithm. The binary hypothesis Z-score of specific chromosomes in each sample was determined; the normal range for chromosomes was $3<z<3$. Briefly, samples with a Z-score $\geq 3.0$ for these chromosomes was classified as positive, whereas a Z-score $<3.0$ was classified as negative for the indicated trisomy.

\section{Invasive procedure and karyotyping}

Pregnant women with positive screening results on NIPT consented to undergo an invasive prenatal diagnosis procedure, which is the gold standard for diagnosing chromosome aneuploidies. Karyotyping was performed on cell cultures from trophoblastic or fetal cells. Routine fixation, production and dyeing treatment, microscopic examination, and analysis of the karyotype (G-banding) of amniotic fluid were performed. The resolution of metaphase G-banding was 320 bands.

\section{Follow-up}

Prenatal and postnatal telephone follow-up were conducted to determine whether or not there were false-negative results.

\section{Statistical analyses}

All statistical analyses were performed using SPSS 19.0 software. Data are presented as the mean \pm SD. Analysis of variance was used to compare the differences between different groups. A P-value $<0.05$ was considered statistically significant.

\section{RESULTS}

\section{Efficiency of NIPT for T21/T18/T13}

Among 8594 prenatal women who received effective NIPT results, 44 had positive results for $\mathrm{T} 21 / \mathrm{T} 18 / \mathrm{T} 13$, including 30 cases with T21, 9 cases with T18, and 5 cases with T13. After informed consent, the gravidas accepted prenatal diagnosis by amniotic fluid cell analysis. Table 1 shows the prenatal diagnosis results. The detection rate, specificity, and positive predictive value (PPV) was $97.37 \%, 99.92 \%$, and $82.22 \%$, respectively. After follow-up, we identified 1 false-negative result and 7 false-positive results; the false-positive rate was $0.08 \%$.

\section{Efficiency of NIPT for sex chromosome aneuploidy (SCA)}

The NIPT results indicated that 44 cases had fetal sex chromosome abnormalities, including 2 cases with Klinefelter syndrome $(47, X X Y), 11$ cases with Turner syndrome $(45, X), 14$ cases with $47 X Y Y$ syndrome, and 17 cases with $X X X$ syndrome (47, XXX). After informed consent, 33 gravidas accepted prenatal diagnosis via amniocentesis. As shown in Table 2, 18 cases were confirmed to be true-positive results

\begin{tabular}{|l|l|l|l|l|l|l|l|}
\hline \multicolumn{2}{|l|}{ Table 1.44 cases of NIPT-positive results for T21/T18/T13 } \\
\hline NIPT result & $\begin{array}{l}\text { NIPT positive } \\
\text { result }\end{array}$ & True positive & False positive & False negative & Detection rate [\%] & Specificity [\%] & $\begin{array}{l}\text { Positive predictive } \\
\text { value [\%] }\end{array}$ \\
\hline T21 & 30 & 30 & 0 & 1 & $96.77 \%$ & $100 \%$ & $96.77 \%$ \\
\hline T18 & 9 & 6 & 3 & 0 & $100 \%$ & $100 \%$ & $66.67 \%$ \\
\hline T13 & 5 & 1 & 4 & 0 & $100 \%$ & $100 \%$ & $20.00 \%$ \\
\hline Total & 44 & 37 & 7 & 1 & $97.37 \%$ & $99.92 \%$ & $82.22 \%$ \\
\hline
\end{tabular}

\begin{tabular}{|l|l|l|l|l|l|l|}
\hline \multicolumn{2}{l}{ Table 2. 44 cases of NIPT-positive SCA detection results } \\
\hline $\begin{array}{l}\text { NIPT-positive } \\
\text { SCA }\end{array}$ & $\begin{array}{l}\text { Positive NIPT } \\
\text { cases [n] }\end{array}$ & $\begin{array}{l}\text { Karyotype } \\
\text { validated }\end{array}$ & True positive & False positive & $\begin{array}{l}\text { Positive predictive } \\
\text { value [\%] }\end{array}$ & $\begin{array}{l}\text { Without } \\
\text { karyotype validated }\end{array}$ \\
\hline $47, \mathrm{XXY}$ & 2 & 2 & 2 & 0 & $100.00 \%$ & 0 \\
\hline $45, \mathrm{X}$ & 11 & 9 & 4 & 5 & $44.44 \%$ & 2 \\
\hline $47, \mathrm{XYY}$ & 14 & 10 & 5 & 5 & $50.00 \%$ & 4 \\
\hline $47, \mathrm{XXX}$ & 17 & 12 & 7 & 5 & $58.33 \%$ & 5 \\
\hline Total & 44 & 33 & 18 & 15 & $54.55 \%$ & 11 \\
\hline
\end{tabular}


and 15 cases were confirmed to be false-positive results. The PPV of NIPT for fetal SCAs was $54.55 \%$. Table 3 shows the PPV of NIPT for different types of SCAs. The PPV for Turner syndrome was the lowest (44.44\%).

\section{Distribution of the indications}

Among 8594 prenatal women who received NIPT results, we diagnosed a total of 88 cases with abnormal NIPT results. Different detection pointers detect different positive NIPT numbers. The positive distribution of each indication through NIPT was different (Tab. 3).

\section{DISCUSSION}

Aneuploidies, which are chromosomal abnormalities characterized by anomalous of chromosomes than the 23 pairs normally present in humans,concluding Down syndrome (trisomy 21 or T21), Edward syndrome (trisomy 18 or T18), Patau syndrome (trisomy 13 or T13), Turner syndrome $(45, X)$, Klinefelter syndrome $(47, X X Y)$, Triple $X$ syndrome $(47, X X X)$ and $47, X Y Y$ syndrome $(47, X Y Y)$. These chromosomal anomalies are contributed to the morbidity or death of both childhood and adulthood. [12] During recent years, NIPT has been increasingly used in the detection of common chromosome aneuploidies for T21, T18, and T13 in fetuses during prenatal screening in many countries [13]. NIPT is helpful for the early detection of birth defects to reduce the incidence of birth defects. In addition, it can reduce the occurance of spontaneous miscarriages due to invasive prenatal testing such as amniocentesis and expand the prenatal testing options as well as reduce the need for invasive testing [14-17].

According to our clinical data from 8594 gravidas, we confirmed that the detection rate, specificity, and PPV were $97.37 \%, 99.92 \%$, and $82.22 \%$, respectively, which were in accordance with other studies [16-19]. Moreover, the specificity of the prior serologic screening test for T21 was $29.13 \%$ compared to $100 \%$ for NIPT; the PPV was $96.77 \%$. Compared with conventional methods, the specificity and PPV of NIPT in screening for T21 were greater. For T18, the specificity was $98.20 \%$ for conventional screening [20] compared to
$100 \%$ for NIPT; the PPV was $66.77 \%$. The PPV for T13 was $20.00 \%$; the result was not satisfactory, suggesting that large samples are still needed to focus on the performance of NIPT for T13 screening.

NIPT is used in prenatal screening for fetal SCAs; however, positive SCA results are not a direct indication to induce labor. Our results were positive for SCAs in 44 cases; there were 18 true-positive cases. The overall true-positive rate for SCA detection by NIPT was $54.55 \%$. Among the different types of SCAs, the PPV for Turner syndrome was the lowest (44.44\%). Prediction of other SCAs was relatively accurate; the PPVs of pregnancies with $47, \mathrm{XXX}, 47, \mathrm{XXY}$, and $47, \mathrm{XYY}$ karyotypes predicted by NIPT were $58.33 \%, 100 \%$, and $50.00 \%$, respectively. Cheung [21] reported that the falsepositive rate of monosomy $X$ karyotype detected by NIPT was $62 \%$, which is much higher compared to the false-rates for 47 , $X X X, 47, X X Y$, and 47, XYY karyotypes. Therefore, our findings demonstrated that NIPT was a more accurate predictor of triple $X$ and Klinefelter syndrome compared with fetal Turner syndrome. In addition, patients with SCAs are usually mildly symptomatic during the neonatal period without any physical or intellectual disabilities. The traditional method of follow-up could not achieve accurate results of SCAs disease. Therefore, it is necessary to improve the detection rate of sex chromosomes by NIPT and reduce the false-positive rate.

Our results suggest that NIPT is suitable for high- and intermediate-risk prenatal screening. It has been reported that among 56 Down syndrome fetuses, 14\% were associated with intermediate-risk mothers [22]. In our study, NIPT for intermediate-risk samples detected 10 positive cases, among which 7 were true positive $(70.00 \%)$. NIPT for low-risk samples detected 12 positive cases, among which 7 were true positive (58.33\%).

The current experimental studies involving clinical effectiveness have focused on high-risk populations, such as advanced maternal age, and screening to reduce unnecessary interventional prenatal diagnosis, which have not been fully validated in low-risk populations. Based on our data, the experimental failure rate was not significantly increased in low-risk groups and the false-positive rate

Table 3. The positive distribution of each indication for 88 cases with NIPT positive results

\begin{tabular}{|l|l|l|l|}
\hline Indication & Cases [\%] & Positive NIPT cases [\%] & True positive [\%] \\
\hline High-risk prenatal screening & $2614(30.42 \%)$ & $32(35.95 \%)$ & $20(60.61 \%)$ \\
\hline Intermediate-risk prenatal screening & $2111(24.56 \%)$ & $10(11.24 \%)$ & $7(70.00 \%)$ \\
\hline Low-risk prenatal screening & $1513(17.61 \%)$ & $12(13.48 \%)$ & $7(58.33 \%)$ \\
\hline Ultrasound structural abnormality & $572(15.65 \%)$ & $9(10.11 \%)$ & $6(66.67)$ \\
\hline Advanced maternal age ( $\geq 35)$ & $973(11.32 \%)$ & $19(1.95 \%)$ & $11(57.89 \%)$ \\
\hline Abnormal pregnancy & $590(6.87 \%)$ & $5(21.35 \%)$ & $3(60.00 \%)$ \\
\hline Assisted reproduction conception & $221(2.57 \%)$ & $2(2.25 \%)$ & $1(50.00 \%)$ \\
\hline
\end{tabular}


was similar to the high-risk group. It is our opinion that if guidelines expand NIPT recommendations to include low-risk patients, the implications of significantly increased screening should be further explored.

The development and application of NIPT in southern and southeastern China has advanced further than in western and northern China; there are clearly regional differences in the use of NIPT [23]. Our study was conducted mainly in northwestern China. We found that there were fewer pregnant women undergoing NIPT, with the main reason being cost. The costs for NIPT screening are currently higher than for other screening protocols [24]. If the technology can reduce the cost of testing, more pregnant women will undergo NIPT and will gradually replace serologic screening.

The accuracy, specificity, high efficiency, and acceptance of NIPT has great advantages, which can effectively avoid the birth defects and improve the quality of the birth population compared with the classical invasion testing. But the disadvantage of NIPT is obvious. The false positives could occur because of NIPT [17]. On this account, we must use invasive testing to confirm positive results before any irreversible procedure is performed. It can avoid the harm of patients' interests from detection errors [12].

\section{CONCLUSIONS}

We should deepen mining and analysis of the clinical data and explore ways to use NIPT. It is recommended that the NIPT guidelines be extended to low-risk patients to further explore the significance of a significant increase in screening and we can consider NIPT as an important supplementary diagnosis to conventional invasion testing for detection of trisomy 13, 18, 21 and sex chromosome aneuploidies.

\section{Funding}

This study was supported by National Key Research and DevelopmentProgram ofChina, 2016YFC1000700;2016YFC1000703.

\section{REFERENCES}

1. Hartwig TS, Ambye L, Sørensen S, et al. Discordant non-invasive prenatal testing (NIPT) - a systematic review. Prenat Diagn. 2017; 37(6): 527-539, doi: 10.1002/pd.5049, indexed in Pubmed: 28382695.

2. Gil MM, Quezada MS, Revello R, et al. Analysis of cell-free DNA in maternal blood in screening for fetal aneuploidies: updated meta-analysis. Ultrasound Obstet Gynecol. 2015; 45(3): 249-266, doi: 10.1002/uog.14791, indexed in Pubmed: 25639627.

3. Norton ME, Jacobsson Bo, Swamy GK, et al. Cell-free DNA analysis for noninvasive examination of trisomy. N Engl J Med. 2015; 372(17): 15891597, doi: 10.1056/NEJMoa1407349, indexed in Pubmed: 25830321.

4. Dar P, Curnow KJ, Gross SJ, et al. Clinical experience and follow-up with large scale single-nucleotide polymorphism-based noninvasive prenatal aneuploidy testing. Am J Obstet Gynecol. 2014; 211(5): 527.e1-527.e17, doi: 10.1016/j.ajog.2014.08.006, indexed in Pubmed: 25111587.

5. Zhang $\mathrm{H}$, Gao Y, Jiang F, et al. Non-invasive prenatal testing for trisomies 21, 18 and 13: clinical experience from 146,958 pregnancies. Ultrasound Obstet Gynecol. 2015; 45(5):530-538, doi: 10.1002/uog.14792, indexed in Pubmed: 25598039.
6. Gil M, Quezada MS, Revello R, et al. Analysis of cell-free DNA in maternal blood in screeing for fetal aneuploidied updated metaanalysis. Ultrasound Obstet Gynecol. 2015; 45: 249-66.

7. Ashoor G, Syngelaki A, Wagner M, et al. Chromosome-selective sequencing of maternal plasma cell-free DNA for first-trimester detection of trisomy 21 and trisomy 18. Am J Obstet Gynecol. 2012; 206(4): 322.e1322.e5, doi: 10.1016/j.ajog.2012.01.029, indexed in Pubmed: 22464073.

8. Bianchi DW, Platt LD, Goldberg JD, et al. MatErnal BLood IS Source to Accurately diagnose fetal aneuploidy (MELISSA) Study Group. Genome-wide fetal aneuploidy detection by maternal plasma DNA sequencing. Obstet Gynecol. 2012; 119(5): 890-901, doi: 10.1097/AOG.0b013e31824fb482, indexed in Pubmed: 22362253.

9. Palomaki GE, Kloza EM, Lambert-Messerlian GM, et al. DNA sequencing of maternal plasma to detect Down syndrome: an international clinical validation study. Genet Med. 2011; 13(11): 913-920 doi: 10.1097/GIM.0b013e3182368a0e, indexed in Pubmed: 22005709.

10. Taylor-Phillips S, Freeman K, Geppert J, et al. Accuracy of non-invasive prenatal testing using cell-free DNA for detection of Down, Edwards and Patau syndromes: a systematic review and meta-analysis. BMJ Open. 2016; 6(1): e010002, doi: 10.1136/bmjopen-2015-010002, indexed in Pubmed: 26781507.

11. American College of Obstetricians and Gynecologists Committee on Genetics. Committee opinion no. 640: noninvasive prenatal testing for fetal aneuploidy. Obstetrics \& Gynecology. 2015; 126(3): e31-e37.

12. Forest JC. Diagnostic Test Accuracy Review : Genomics-based non-invasive prenatal testing for detection of fetal chromosomal aneuploidy in pregnant women.[J]. Journal of Agricultural \& Food Chemistry. 2007; 55(22): 8851-8856.

13. Kellogg $G$, Slattery $L$, Hudgins $L$, et al. Attitudes of mothers of children with down syndrome towards noninvasive prenatal testing. J Genet Couns. 2014; 23(5): 805-813, doi: 10.1007/s10897-014-9694-7, indexed in Pubmed: 24481673.

14. van Schendel RV, van El CG, Pajkrt E, et al. Implementing non-invasive prenatal testing for aneuploidy in a national healthcare system: global challenges and national solutions. BMC Health Serv Res. 2017; 17(1): 670, doi: 10.1186/s12913-017-2618-0, indexed in Pubmed: 28927451.

15. Li R, Wan J, Zhang Y, et al. Detection of fetal copy number variants by non-invasive prenatal testing for common aneuploidies. Ultrasound Obstet Gynecol. 2016; 47(1): 53-57, doi: 10.1002/uog.14911, indexed in Pubmed: 26033469.

16. Song Y, Liu C, Qi H, et al. Noninvasive prenatal testing of fetal aneuploidies by massively parallel sequencing in a prospective Chinese population. Prenat Diagn. 2013; 33(7): 700-706, doi: 10.1002/pd.4160, indexed in Pubmed: 23703459.

17. Mersy E, de Die-Smulders CEM, Coumans ABC, et al. Advantages and Disadvantages of Different Implementation Strategies of Non-Invasive Prenatal Testing in Down Syndrome Screening Programmes. Public Health Genomics. 2015; 18(5): 260-271, doi: 10.1159/000435780, indexed in Pubmed: 26202817.

18. Norton ME, Jacobsson Bo, Swamy GK, et al. Cell-free DNA analysis for noninvasive examination of trisomy. N Engl J Med. 2015; 372(17): 1589 1597, doi: 10.1056/NEJMoa1407349, indexed in Pubmed: 25830321.

19. Zhang $\mathrm{H}$, Gao $\mathrm{Y}$, Jiang $\mathrm{F}$, et al. Non-invasive prenatal testing for trisomies 21, 18 and 13: clinical experience from 146,958 pregnancies. Ultrasound Obstet Gynecol. 2015; 45(5): 530-538, doi: 10.1002/uog.14792, indexed in Pubmed: 25598039.

20. Qiang R, Cai Na, Wang X, et al. Detection of trisomies 13 , 18 and 21 using non-invasive prenatal testing. Exp Ther Med. 2017; 13(5): 2304-2310, doi: 10.3892/etm.2017.4272, indexed in Pubmed: 28565842.

21. Cheung SW, Patel A, Leung TY. Accurate description of DNA-based noninvasive prenatal screening. N Engl J Med. 2015; 372(17): 1675-1677, doi: 10.1056/NEJMc1412222, indexed in Pubmed: 25830325.

22. Yu B, Lu BY, Zhang B, et al. Overall evaluation of the clinical value of prenatal screening for fetal-free DNA in maternal blood. Medicine (Baltimore). 2017; 96(27): e7114, doi: 10.1097/MD.0000000000007114, indexed in Pubmed: 28682865.

23. Zhai J, Cai W, Li C, et al. Survey of attitudes of Chinese perinatologists and obstetricians toward non-invasive prenatal genetic testing. J Obstet Gynaecol Res. 2016;42(11): 1445-1450, doi: 10.1111/jog.13087, indexed in Pubmed: 27527689.

24. Song Y, Liu C, Qi H, et al. Noninvasive prenatal testing of fetal aneuploidies by massively parallel sequencing in a prospective Chinese population. Prenat Diagn. 2013; 33(7): 700-706, doi: 10.1002/pd.4160, indexed in Pubmed: 23703459. 